\title{
Linezolid use in German acute care hospitals: results from two consecutive national point prevalence surveys
}

\author{
Tobias Siegfried Kramer ${ }^{1,2}$, Frank Schwab ${ }^{1,2}$, Michael Behnke ${ }^{1,2}$, Sonja Hansen ${ }^{1,2}$, Petra Gastmeier ${ }^{1,2}$ and \\ Seven Johannes Sam Aghdassi ${ }^{1,2^{*}}$ (1)
}

\begin{abstract}
Background: Linezolid belongs to a reserve group of antibiotics. In recent years, reports on linezolid resistance in gram-positive cocci have become more frequent. Overuse of linezolid is a relevant factor for resistance development. The objective of this study was to describe current prescription practices of linezolid in German hospitals and identify targets for antimicrobial stewardship interventions.

Methods: We analyzed all linezolid prescriptions from the datasets of the consecutive national point prevalence surveys performed in German hospitals in 2011 and 2016. In both surveys, data on healthcare-associated infections and antimicrobial use were collected following the methodology of the European Centre for Disease Prevention and Control.

Results: Overall, the percentage of linezolid among all documented antimicrobials increased significantly from 2011 to 2016 ( $p$ < 0.01). In 2011, 0.3\% (119 of 41,539) patients received linezolid, in 2016 this proportion was significantly higher (0.4\%; 255 of 64,412 patients; $p<0.01)$. In 2016, intensive care units (ICUs) were the wards most frequently prescribing linezolid. The largest proportion of patients receiving linezolid were non-ICU patients. Roughly 38\% of linezolid prescriptions were for treatment of skin/soft tissue and respiratory tract infections. In 2016, linezolid was administered parenterally in $70 \%(n=179)$ of cases. Multivariable analysis showed that the ward specialty ICU posed an independent risk factor, while Northern and Southwestern regions in Germany were independent protective factors for a high rate of linezolid prescriptions.
\end{abstract}

Conclusions: In conclusion, we detected potentials for improving linezolid prescription practices in German hospitals. Given the emergence of linezolid resistance, optimization of linezolid use must be a target of future antimicrobial stewardship activities.

Keywords: Linezolid, Antimicrobial use, Antimicrobial stewardship, Surveillance, Point prevalence survey

\section{Background}

Linzezolid is an antimicrobial substance belonging to the group of oxazolidinones. It is effective against grampositive cocci, such as staphylococci and enterococci. In the early 2000s, linezolid was introduced into the German market. It was licensed for the treatment of certain bacterial infections caused by methicillin-resistant

\footnotetext{
* Correspondence: seven-johannes-sam.aghdassi@charite.de

${ }^{1}$ Charité - Universitätsmedizin Berlin, corporate member of Freie Universität Berlin, Humboldt-Universität zu Berlin, and Berlin Institute of Health, Institute of Hygiene and Environmental Medicine, Berlin, Germany

${ }^{2}$ National Reference Center for Surveillance of Nosocomial Infections, Berlin, Germany
}

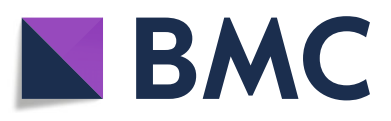

(c) The Author(s). 2019 Open Access This article is distributed under the terms of the Creative Commons Attribution 4.0 International License (http://creativecommons.org/licenses/by/4.0/), which permits unrestricted use, distribution, and reproduction in any medium, provided you give appropriate credit to the original author(s) and the source, provide a link to the Creative Commons license, and indicate if changes were made. The Creative Commons Public Domain Dedication waiver (http://creativecommons.org/publicdomain/zero/1.0/) applies to the data made available in this article, unless otherwise stated.
Staphylococcus aureus (MRSA) and vancomycinresistant enterococci (VRE). These included the treatment of pneumonia caused by MRSA [1-3], as well as severe skin and soft tissue infections $[3,4]$. With its classification as a reserve group antibiotic by the World Health Organization, many applications of linezolid have to be regarded as off-label. This especially applies to the treatment of bone and joint infections [5-9], peritonitis [10], bacteremia [11-14], and endocarditis [15]. Additionally, the excellent oral bioavailability opened new opportunities [16]. 
Resistance against linezolid in gram-positive cocci is caused by a diverse selection of mutations, which have been identified since the introduction of the drug into the market [17]. Cases of linezolid-resistant enterococci and staphylococci have been reported from outbreaks as well as clinical isolates with increasing frequency [1820]. Resistance against linezolid is also increasing in Germany [21-23]. Prior treatment with linezolid has been identified as a risk factor for linezolid resistance [24]. Given the relevance of this topic and the lack of robust epidemiological data on the subject, the objective of our study was to describe the current practices of linezolid use in German hospitals and to identify targets for antimicrobial stewardship efforts to promote the prudent use of linezolid.

\section{Methods}

Two point prevalence surveys (PPSs) were conducted in acute care hospitals in Germany in the years 2011 and 2016. Data collection in the participating hospitals was executed by trained local hospital staff. For both surveys, training was organized by the German National Reference Center for Surveillance of Nosocomial Infections in special one-day courses to ensure methodological consistency. Per participating hospital, one person had to attend at least one training course. The training comprised of a detailed presentation of the scope and methodology of the survey, and included case vignettes to be completed by all participants. All data were collected in alignment with the methodology and definitions provided by the European Centre for Disease Prevention and Control (ECDC) [25]. In all cases, participation was on a voluntary basis. In the PPSs, data on healthcareassociated infections (HAIs), antimicrobial use, as well as further indicators of infection prevention and control and antimicrobial stewardship, as defined in the ECDC protocol, were collected. Only patients hospitalized at the time of the survey were included. Following a point prevalence approach, only information available at the time of the survey was collected. The specifics of data collection and management have been described elsewhere in more detail [26-28].

From the data gathered, we extracted all linezolid prescriptions, which were recorded by data collectors, for further analysis. Hospitals and wards, which had at least one patient receiving linezolid, were identified and compared to hospitals and wards where linezolid was not used. Analyses were conducted for all hospitals and separately for a core group of 46 hospitals, which took part in both surveys (2011 and 2016). Following the ECDC methodology, every antimicrobial prescription recorded in the survey had to be allocated to an indication. The ECDC protocol differentiated between antimicrobial use for treatment of infections, prophylactic antimicrobial use and antimicrobial use for other or unknown reasons. Treatment was further segregated into treatment for hospital-acquired infections, community-acquired infections and infections acquired in long-term care facilities. We analyzed the indications for linezolid use and if used for treatment of an infection, we described the site of the infection. Furthermore, data on the route of application were collected and analyzed.

As mentioned above, participating hospitals collected data on HAIs and antimicrobial use. However, the two data sets (HAIs and antimicrobial use) cannot be linked without limitations, since definitions for the HAIs did not correspond with definitions for the site of infection in antimicrobial use for treatment. This means, that patients may have documented use of an antimicrobial for treatment of a hospital-acquired infection, but no corresponding HAI was documented, since the ECDC criteria for an active HAI were not fulfilled. In a similar manner, patients with ECDC HAIs may not have a recorded antimicrobial prescription for a hospital-acquired infection. The background is that the indication for antimicrobial use was supposed to reflect the prescribers' opinion, whereas the ECDC HAIs required the fulfilment of a set of criteria. Despite this difficulty, we analyzed whether a HAI was documented in patients receiving linezolid, and if a pathogen for the HAI was recorded.

Chi-squared test and Mann-Whitney $U$ test were utilized for univariable analysis. Furthermore, we conducted a multivariable logistic regression analysis to identify predictors of a high rate of linezolid use among all antimicrobials in wards with at least one patient receiving linezolid. A high rate was defined as being equal or greater the 75th percentile of all wards with at least one linezolid prescription. To determine this outcome, we performed a multivariable logistic regression analysis by variable selection stepwise forward. The following parameters were included in the model:

- At the hospital level: hospital type; hospital ownership; number of hospital beds; presence of designated staff for antimicrobial stewardship; number of blood cultures per 100 patient days; number of stool tests for Clostridioides difficile infection per 100 patient days; participation in a surveillance network for Clostridioides difficile infections; participation in a surveillance network for antimicrobial consumption; participation in a surveillance network for antimicrobial resistance; presence of guidelines for antimicrobial use; presence of training for antimicrobial use; presence of bundles for antimicrobial use; presence of checklists for antimicrobial use; presence of audits for antimicrobial use; presence of surveillance of 
antimicrobial use; presence of feedback of data on antimicrobial use.

- At the ward level: ward specialty; number of ward beds; prevalence of patients with antimicrobial use; percentage of antimicrobials with a reason in notes (i.e. documented indication); presence of a postprescription review of antimicrobials within $72 \mathrm{~h}$.

All analyses were conducted with SPSS (IBM SPSS statistics, Somer, NY, USA) and OpenEpi (Open Source Epidemiologic Statistics for Public Health, Version. www.OpenEpi.com, updated 2013/04/06, accessed 2019/ 06/07). A $p$-value of less than 0.05 was considered statistically significant.

\section{Ethical approval}

The German Protection against Infection Act ("Infektionsschutzgesetz") requires all hospitals in Germany to collect data on HAIs and antimicrobial use. Since all data collected were anonymized and handled in accordance with the German Protection against Infection Act, ethical approval and informed consent were not required.

\section{Results}

A total of 132 hospitals took part in the PPS 2011, and 218 hospitals participated in the survey in 2016. The prevalence of patients with antimicrobial use (pooled mean) was $25,5 \%$ in 2011 (10,607 of 41,539 patients) and $25.9 \%$ in 2016 (16,688 of 64,412 patients). The percentage of patients receiving linezolid increased significantly $(p<0.01)$ from $0.3 \%$ (119 of 41,539 patients) in 2011 to $0.4 \%$ (255 of 64,412 patients) in 2016. Collectively, the number of linezolid prescriptions among all antimicrobial prescriptions increased significantly $(n=119(0.8 \%)$ in 2011 vs. $n=255(1.2 \%)$ in 2016; $p<0.01)$. While in $201137.1 \%$ hospitals $(n=49)$ documented patients with linezolid, this increased to $43.6 \%(n=95)$ in 2016. The number of wards which used linezolid significantly increased from 2011 to 2016 (98 vs. 212; p < 0.01). The median percentage of linezolid among all antimicrobial prescriptions in wards with at least one linezolid prescription decreased from 9.5\% (interquartile range: 6.513.6) to 9.1\% (interquartile range: 6.7-14.3). Regional differences in the use of linezolid were detected, with a significant increase in the percentage of participating wards that used linezolid in the West of Germany (Table 1). The majority of wards prescribing Linezolid in 2016 were intensive care units (ICUs) $(37.3 \%(n=79))$, surgical non-ICU wards $(28.3 \%(n=60))$ and medical non-ICU wards $(23.6 \%(n=50))$. The majority of patients receiving linezolid were medical and surgical nonICU patients. In 2016, roughly $50.6 \%(n=129)$ of prescriptions of linezolid were for treatment of hospital- acquired infections. Among all treatments, treatment of skin and soft tissue infections remained a common indication from $2011(20.2 \%(n=21))$ to $2016(23.7 \%$ $(n=55))$. Lower respiratory tract infections made up a smaller proportion of documented indications for linezolid in $2016(18.1 \%(n=42))$ when compared to 2011 $(26.0 \%(n=27))$. In 2016, Bone and joint infections $(12.1 \% \quad(n=28))$, bacteremia $(11.6 \% \quad(\mathrm{n}=27))$ and intraabdominal infections $(9.9 \%(n=23))$ represented a large part of the remaining indications for treatment with linezolid (Table 2). On non-ICU wards, 44.2\% ( $n=$ 69) of linezolid was prescribed orally (Table 3 ).

In patients included in the survey 2016 with linezolid use and HAIs as defined by the ECDC, a total of 132 pathogens were documented. Among the most frequently isolated pathogens were enterococci $(n=44 ; 10$ of which with resistance against vancomycin), coagulase negative staphylococci $(n=21)$ and Staphylococcus aureus ( $n=19 ; 12$ of which with resistance against methicillin) (Additional file 1: Table S1"). Structural and process parameters of antimicrobial use and antimicrobial stewardship which were only collected in the PPS 2016 (Additional file 1: Table S2), as well as data on a separate analysis of the core group of 46 hospitals participating in both surveys can be also found in the online-supplement (Additional file 1: Table S3) of this article.

Multivariable logistic regression revealed that the ward specialty ICU was significantly associated with a high rate ( $275 \%$ percentile) of linezolid prescriptions among all antimicrobial prescriptions in wards with at least one patient receiving linezolid. Conversely, the regions North and Southwest, as well as a $1 \%$ increase in the prevalence of patients with antimicrobial use, were factors significantly decreasing the likelihood of a high rate of linezolid among all antimicrobials. Further parameters, which related to antimicrobial stewardship activities, were not demonstrated to have a significant effect on the rate of linezolid prescriptions (Table 4).

\section{Discussion}

Overall, we did not observe a drastic change in the use of linezolid in German hospitals participating in the two PPSs. Although significantly more patients received linezolid in 2016 than in 2011, the median of the proportion of linezolid among all antimicrobials prescribed in wards with linezolid use slightly decreased, while the $75 \%$ percentile increased. This observation could be explained by a few wards with intensified use of linezolid, compared to a larger number of wards trying to restrict linezolid use. Furthermore, a larger proportion of the participating hospitals and wards documented at least one patient receiving linezolid in 2016, when compared to 2011. This development could have been triggered by the reported increase in HAIs caused by VRE in 


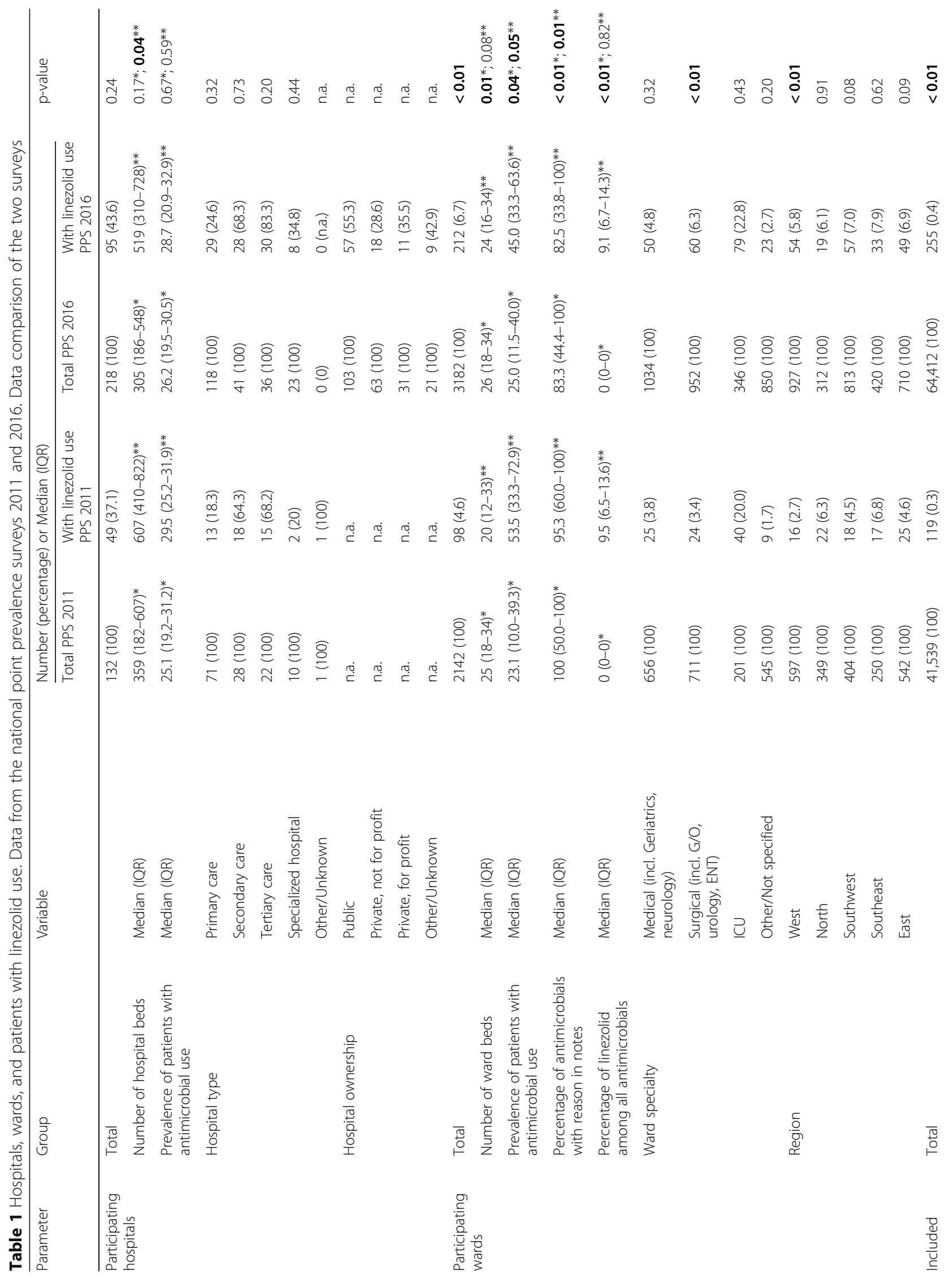




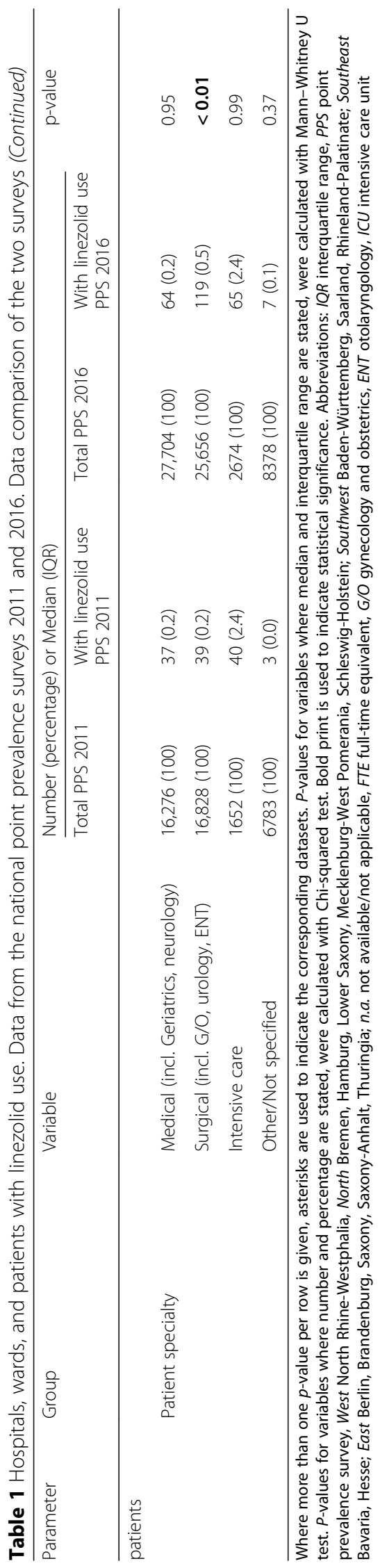




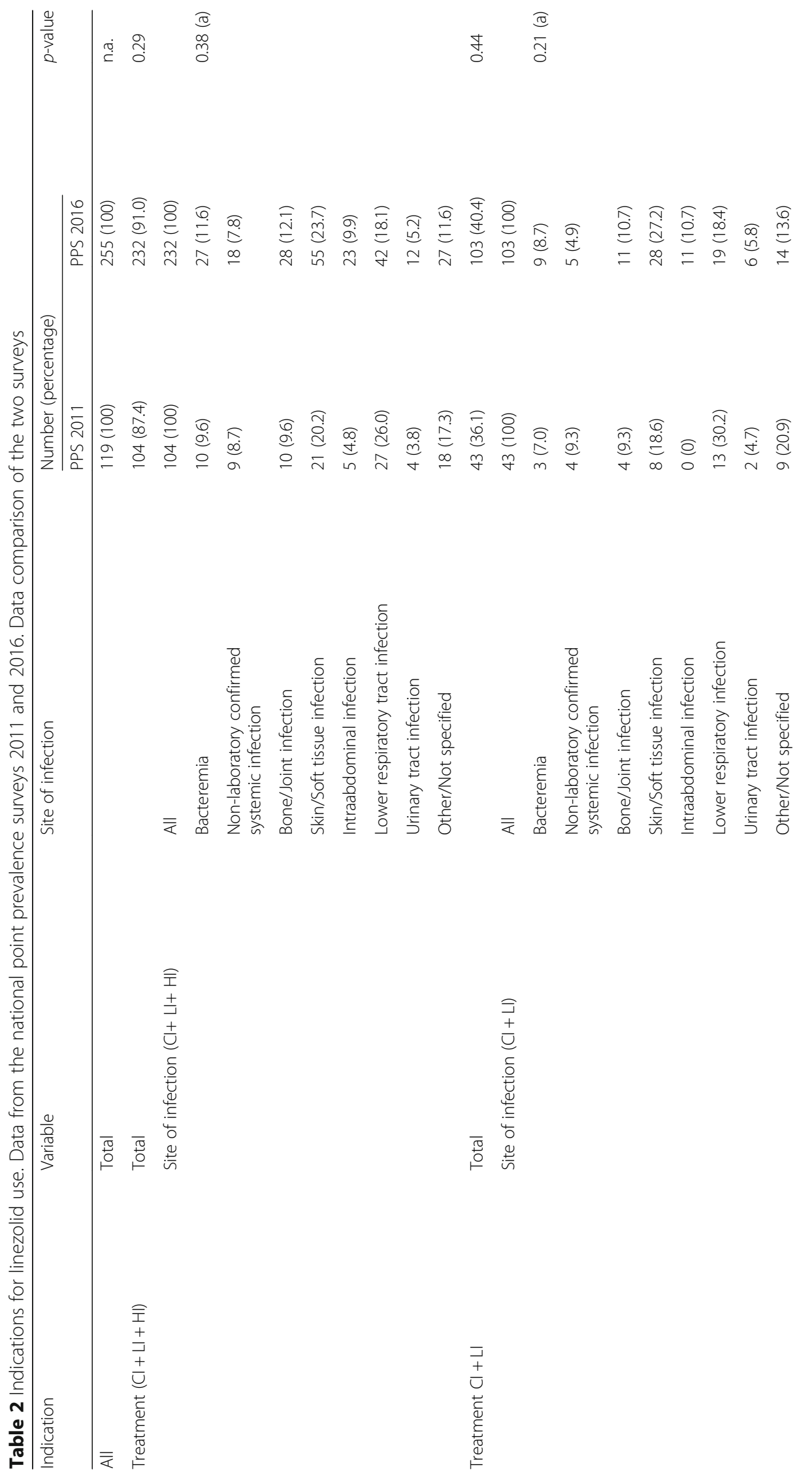


Kramer et al. Antimicrobial Resistance and Infection Control $\quad$ (2019) 8:159

Page 7 of 11

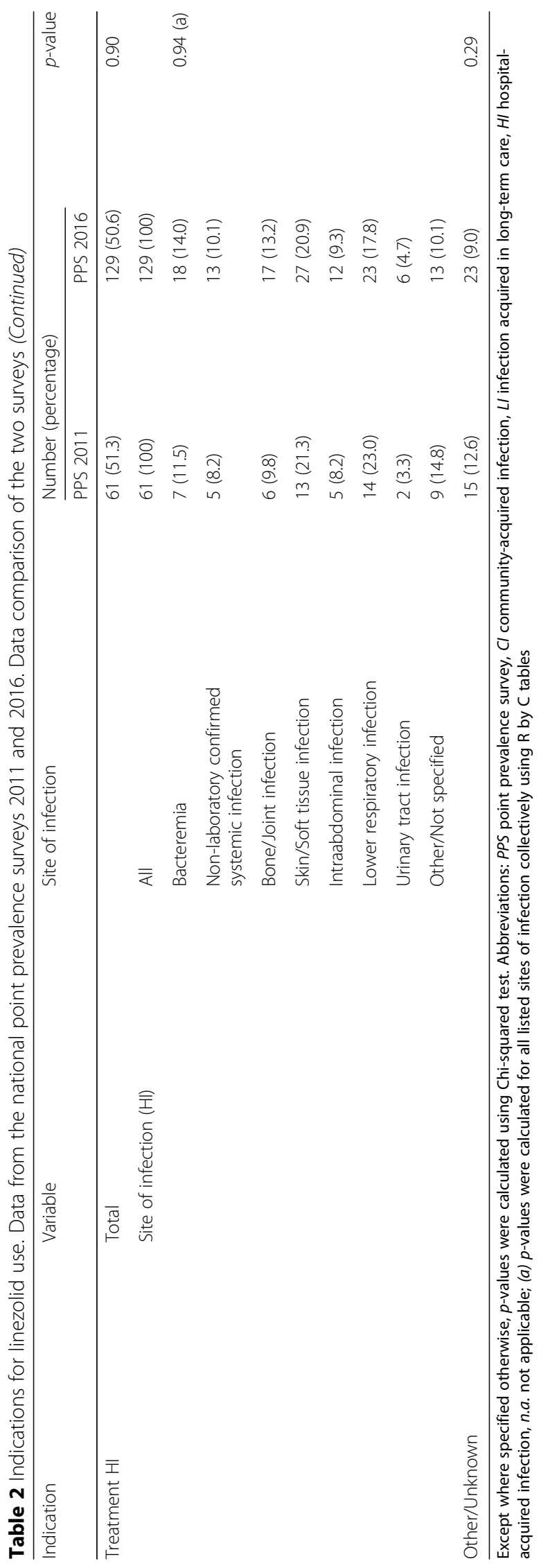


Table 3 Antimicrobial prescriptions and linezolid prescriptions. Data from the national point prevalence surveys 2011 and 2016. Data comparison of the two surveys

\begin{tabular}{|c|c|c|c|c|c|}
\hline \multirow[t]{2}{*}{ Parameter } & \multirow[t]{2}{*}{ Variable } & \multirow[t]{2}{*}{ Specification } & \multicolumn{2}{|c|}{ Number (percentage) } & \multirow[t]{2}{*}{$p$-value } \\
\hline & & & PPS 2011 & PPS 2016 & \\
\hline Antimicrobial prescriptions (all) & & & $14,076(100)$ & $22,086(100)$ & n.a. \\
\hline Linezolid prescriptions (all) & & & $119(0.8)$ & $255(1.2)$ & $<0.01$ \\
\hline \multirow[t]{5}{*}{ Linezolid prescriptions (all wards) } & Total & & $119(100)$ & $255(100)$ & n.a. \\
\hline & Dosage & $2 \times 600 \mathrm{mg}$ & n.a. & $227(89.0)$ & n.a. \\
\hline & & All other dosages & n.a. & $28(11.0)$ & \\
\hline & Route of application & Parenteral & $87(73.1)$ & $179(70.2)$ & 0.57 \\
\hline & & Oral & $32(26.9)$ & $76(29.8)$ & \\
\hline \multirow{3}{*}{$\begin{array}{l}\text { Linezolid prescriptions in } \\
\text { non-ICU wards }\end{array}$} & Total & & $67(56.3)$ & $156(61.2)$ & n.a. \\
\hline & Route of application & Parenteral & $36(53.7)$ & $87(55.8)$ & 0.78 \\
\hline & & Oral & $31(46.3)$ & $69(44.2)$ & \\
\hline
\end{tabular}

$P$-values for variables were calculated using Chi-squared test. Bold print is used to indicate statistical significance. Abbreviations: PPS point prevalence survey, ICU intensive care unit, n.a. not available/not applicable

Germany [29]. Observed regional differences in the prevalence of linezolid use might be explained by existing regional differences in the proportion of MRSA and VRE in HAIs in Germany [29, 30].

In 2011, a large number of patients treated with linezolid were hospitalized in ICUs. In 2016, this was still true and could be interpreted as an indication that linezolid is primarily prescribed for treatment of severe infections, such as pneumonia caused by MRSA [31]. However, patients in surgical non-ICU wards were the second most common patient group to receive linezolid in 2016. In this patient group, off-label use of linezolid appears likely [32]. Recommendations by the Surgical Infection Society and the Infectious Diseases Society of America include linezolid as an option in the treatment of complicated intraabdominal infections [33]. However, high quality evidence on this recommendation is scarce. Furthermore, the sole application of international guidelines or guidelines from another country does not consider the underlying epidemiological situation of drug resistance in Germany [34, 35] and therefore, is not always appropriate.
While the above-listed indications and off-label use of linezolid represent one aspect of evaluating linezolid use, dosing and route of application are other important factors. According to our data, linezolid was adequately prescribed as $600 \mathrm{mg}$ twice daily in almost $90 \%$ of cases. However, more than half of patients outside of ICUs received linezolid intravenously. This either reflects the severe morbidity of these patients, or shows a lack of knowledge of pharmacokinetics and pharmacodynamics, given the good oral bioavailability of linezolid [16]. Adverse events, especially in patients undergoing parenteral treatment with linezolid for longer than 10 days, have been repeatedly described [36, 37]. Sensitizing prescribers for the adverse effects of linezolid use can be an effective intervention to decrease linezolid use and establish less harmful therapeutic regimens. When this is done, an emphasis should be placed on a multidisciplinary approach at the matter.

Several reports have identified effective antimicrobial stewardship measures focusing on linezolid that did not only decrease use [38] and costs [39], but also led to a reduction of resistance against linezolid [40]. In this

Table 4 Multivariable analysis for the outcome high rate of linezolid prescriptions per 100 antimicrobial prescriptions of 212 wards with linezolid use in the point prevalence survey 2016

\begin{tabular}{lllll}
\hline Outcome & Parameter & Odds ratio & $95 \%$ confidence intervall & $p$-value \\
\hline $\begin{array}{l}\text { High rate of linezolid prescriptions } \\
\text { per } 100 \text { antimicrobial prescriptions }(\geq 3 \mathrm{Q})\end{array}$ & Prevalence of patients with & 0.94 & $0.92-0.96$ & $<\mathbf{0 . 0 1}$ \\
& antimicrobial use (per 1\% increase) & & $\mathbf{0 . 0 4 - 0 . 7 8}$ \\
& North (region) & 0.19 & $0.19-0.99$ & $\mathbf{0 . 0 2}$ \\
& Southwest (region) & 0.43 & $\mathbf{0 . 0 5}$ \\
& Intensive care unit (ward specialty) & 4.89 & $\mathbf{2 . 0 5 - 1 1 . 7 0}$ \\
\hline
\end{tabular}

Bold print is used to indicate statistical significance. High was defined as greater or equal than the 75 th percentile (3Q). The value for $3 \mathrm{Q}$ was $14.3 \%$. Abbreviations: North Bremen, Hamburg, Lower Saxony, Mecklenburg-West Pomerania, Schleswig-Holstein; Southwest Baden-Württemberg, Saarland, Rhineland-Palatinate 
context, it is important to acknowledge that despite clinical benefits and cost-effectiveness of linezolid, there are multiple alternative treatment options for multidrug resistant staphylococci infections that were demonstrated to lead to non-inferior outcomes [41], while being even more cost-effective [42].

As shown in our multivariable analysis, the ward specialty ICU represented an independent risk factor for a high rate of linezolid prescriptions. This finding could potentially be explained by the general recommendation to reserve linezolid for the therapy of patients with severe infections and high risk for gram-positive multidrug resistant organisms (e.g. MRSA or VRE). In the case of MRSA, alternative effective treatment options are available and a decrease in methicillin-resistance was described for HAIs caused by Staphylococcus aureus in Germany [30]. However, the same does not apply for VRE [29]. Pronounced regional differences were demonstrated in Germany regarding the proportion of vancomycin-resistance in HAIs caused by enterococci. Northern and Southwestern regions of Germany are among the parts of the country with the lowest rates of infections due to VRE [43]. This could represent an explanation for those regions being independent protective factors for a high rate of linezolid use in our multivariable analysis.

\section{Limitations}

Since the national PPSs were not originally designed for linezolid-related analyses, various limitations have to be recognized:

- The data in both surveys were collected mostly by non-prescribers. Therefore, the quality of the collected data is highly dependent on documentation quality by the prescribers and/or interaction with the prescribers. To reduce this confounding effect, the staff collecting data were trained prior to the survey according to the ECDC protocol by members of the German National Center for Surveillance of Nosocomial Infections.

- Participation in the surveys was voluntary. Therefore, centers with a higher motivation to conduct surveillance may be overrepresented. Frequently, these are hospitals with higher rates of HAIs and antimicrobial use. This could conceivably lead to an overestimation with regard to the use of linezolid and other reserve group antibiotics.

- Because of the study design, we were only able to describe pathogens in patients, which fulfilled the requirements for HAIs according to ECDC definitions. In patients with infections, which did not fulfill the ECDC definitions, we cannot make any statement about underlying pathogens.
Definitions for the ECDC HAIs did not correspond with definitions for site of infection in antimicrobial use for treatment. Indication for antimicrobial use reflected the prescribers' opinion, whereas the ECDC HAIs required the fulfilment of a set of criteria. Linkage of the two datasets can only be done with reservations.

\section{Conclusion}

Linezolid is an effective antibacterial substance, but increasing use is associated with resistance. Our data showed that prescription of linezolid is common in German hospitals. Off-label use appears to account for a relevant proportion of prescriptions. Especially surgical non-ICU wards might be a target for antimicrobial stewardship efforts promoting the prudent use of linezolid.

\section{Supplementary information}

Supplementary information accompanies this paper at https://doi.org/10 1186/s13756-019-0617-0.

Additional file 1. Subanalyses and additional data.

\section{Abbreviations}

ECDC: European Centre for Disease Prevention and Control;

HAI(s): Healthcare associated infection(s); ICU(s): Intensive care unit(s); MRSA: Methicillin-resistant Staphylococcus aureus; PPS(s): Point prevalence survey(s); VRE: Vancomycin-resistant enterococci

\section{Acknowledgements}

The authors wish to thank all hospitals that participated in the national point prevalence surveys for their dedication and efforts. Moreover, we wish to express gratitude to the European Centre for Disease Prevention and Control for leading the survey on the European level, and to the German Ministry of Health for funding the survey. The funders had no role in study design, data collection and interpretation, or the decision to submit the work for publication.

\section{Authors' contributions}

TK and SA defined the objectives of the study, led the study design and development, and also drafted the manuscript. MB provided the

programming to establish the IT-infrastructure for conducting the surveys. FS conducted the statistical analyses with input from TK and SA. SH and PG made essential contributions to increase the quality of the manuscript. All authors approved the final version of the manuscript.

\section{Funding}

The German Ministry of Health funded the national point prevalence surveys conducted in 2011 and 2016.

\section{Availability of data and materials}

The datasets, on which all analyses are based, are available from the corresponding author upon reasonable request.

Ethics approval and consent to participate Not applicable, because all data displayed in this publication are surveillancebased data, obtained in accordance with the German Protection against Infection Act ("Infektionsschutzgesetz").

\section{Consent for publication}

Not applicable, because all data displayed in this publication are surveillancebased data, obtained in accordance with the German Protection against Infection Act ("Infektionsschutzgesetz"). 


\section{Competing interests}

The authors declare that they have no competing interests.

Received: 24 June 2019 Accepted: 1 October 2019 Published online: 21 October 2019

\section{References}

1. Chastre J, Blasi F, Masterton RG, Rello J, Torres A, Welte T. European perspective and update on the management of nosocomial pneumonia due to methicillin-resistant Staphylococcus aureus after more than 10 years of experience with linezolid. Clin Microbiol Infect. 2014;20(Suppl 4):19-36.

2. Pletz MW, Burkhardt O, Welte T. Nosocomial methicillin-resistant staphylococcus aureus (MRSA) pneumonia: linezolid or vancomycin? comparison of pharmacology and clinical efficacy. Eur J Med Res. 2010; 15(12):507.

3. Brinkmann A, Rohr AC, Frey OR, Kruger WA, Brenner T, Richter DC, et al. S2k guidelines of the PEG on calculated parenteral initial treatment of bacterial diseases in adults: Focussed summary and supplementary information on antibiotic treatment of critically ill patients. Anaesthesist. 2018;67(12):936-49.

4. Bassetti M, Baguneid M, Bouza E, Dryden M, Nathwani D, Wilcox M. European perspective and update on the management of complicated skin and soft tissue infections due to methicillin-resistant Staphylococcus aureus after more than 10 years of experience with linezolid. Clin Microbiol Infect. 2014;20(s4):3-18.

5. Cobo J, Lora-Tamayo J, Euba G, Jover-Saenz A, Palomino J, del Toro MD, et al. Linezolid in late-chronic prosthetic joint infection caused by grampositive bacteria. Diagn Microbiol Infect Dis. 2013;76(1):93-8.

6. Thompson JM, Saini V, Ashbaugh AG, Miller RJ, Ordonez AA, Ortines RV, et al. Oral-only linezolid-rifampin is highly effective compared with other antibiotics for Periprosthetic joint infection: study of a mouse model. J Bone Joint Surg Am. 2017;99(8):656-65.

7. Gomez J, Canovas E, Banos V, Martinez L, Garcia E, Hernandez-Torres A, et al. Linezolid plus rifampin as a salvage therapy in prosthetic joint infections treated without removing the implant. Antimicrob Agents Chemother. 2011;55(9):4308-10.

8. Abad L, Tafani V, Tasse J, Josse J, Chidiac C, Lustig S, et al. Evaluation of the ability of linezolid and tedizolid to eradicate intraosteoblastic and biofilmembedded Staphylococcus aureus in the bone and joint infection setting. J Antimicrob Chemother. 2019;74(3):625-32.

9. Tornero E, Morata L, Martínez-Pastor JC, Angulo S, Combalia A, Bori G, et al. Importance of selection and duration of antibiotic regimen in prosthetic joint infections treated with debridement and implant retention. J Antimicrob Chemother. 2016;71(5):1395-401.

10. Kajihara T, Nakamura S, Iwanaga N, Oshima K, Hirano K, Miyazaki T, et al. Comparative efficacies of daptomycin, vancomycin, and linezolid in experimental enterococcal peritonitis. J Infect Chemother. 2017;23(7): 498-501.

11. Chuang YC, Lin HY, Chen PY, Lin CY, Chen YC, Wang JT, et al. Survival of patients with Vancomycin-resistant Enterococcus faecium bacteremia treated with conventional or high doses of Daptomycin or linezolid is associated with the rate of bacterial clearance. Crit Care Med. 2018;46(10): 1634-42.

12. Chuang YC, Lin HY, Chen PY, Lin CY, Wang JT, Chang SC. Daptomycin versus linezolid for the treatment of vancomycin-resistant enterococcal bacteraemia: implications of daptomycin dose. Clin Microbiol Infect. 2016; 22(10):890 e1-7.

13. Chuang YC, Wang JT, Lin HY, Chang SC. Daptomycin versus linezolid for treatment of vancomycin-resistant enterococcal bacteremia: systematic review and meta-analysis. BMC Infect Dis. 2014;14:687.

14. Britt NS, Potter EM, Patel N, Steed ME. Effect of Continuous and Sequential Therapy among Veterans Receiving Daptomycin or Linezolid for Vancomycin-Resistant Enterococcus faecium Bacteremia. Antimicrob Agents Chemother. 2017:61(5).

15. San-Juan R, Fernández-Ruiz M, Gasch O, Camoez M, López-Medrano F, Domínguez MÁ, et al. High vancomycin MICs predict the development of infective endocarditis in patients with catheter-related bacteraemia due to methicillin-resistant Staphylococcus aureus. J Antimicrob Chemother. 2017; 72(7):2102-9.

16. Willekens R, Puig-Asensio M, Ruiz-Camps I, Larrosa MN, Gonzalez-Lopez JJ, Rodriguez-Pardo D, et al. Early oral switch to linezolid for low-risk patients with Staphylococcus aureus bloodstream infections: a propensity-matched cohort study. Clin Infect Dis. 2018.

17. Pfaller MA, Mendes RE, Streit JM, Hogan PA, Flamm RK. Five-Year Summary of In Vitro Activity and Resistance Mechanisms of Linezolid against Clinically Important Gram-Positive Cocci in the United States from the LEADER Surveillance Program (2011 to 2015). Antimicrob Agents Chemother. 2017. 61(7).

18. Lazaris A, Coleman DC, Kearns AM, Pichon B, Kinnevey PM, Earls MR, et al. Novel multiresistance cfr plasmids in linezolid-resistant methicillin-resistant Staphylococcus epidermidis and vancomycin-resistant Enterococcus faecium (VRE) from a hospital outbreak: co-location of cfr and optrA in VRE. J Antimicrob Chemother. 2017;72(12):3252-7.

19. Gu B, Kelesidis T, Tsiodras S, Hindler J, Humphries RM. The emerging problem of linezolid-resistant Staphylococcus. J Antimicrob Chemother. 2012;68(1):4-11.

20. Dortet L, Glaser P, Kassis-Chikhani N, Girlich D, Ichai P, Boudon M, et al. Long-lasting successful dissemination of resistance to oxazolidinones in MDR Staphylococcus epidermidis clinical isolates in a tertiary care hospital in France. J Antimicrob Chemother. 2017:73(1):41-51.

21. Bender JK, Fleige C, Klare I, Fiedler S, Mischnik A, Mutters NT, et al. Detection of a cfr(B) variant in German Enterococcus faecium clinical isolates and the impact on linezolid resistance in Enterococcus spp. PLoS One. 2016;11(11):e0167042.

22. Bender J, Strommenger B, Steglich M, Zimmermann O, Fenner I, Lensing C, et al. Linezolid resistance in clinical isolates of Staphylococcus epidermidis from German hospitals and characterization of two cfr-carrying plasmids. J Antimicrob Chemother. 2015;70(6):1630-8.

23. Weßels C, Strommenger B, Klare I, Bender J, Messler S, Mattner F, et al. Emergence and control of linezolid-resistant Staphylococcus epidermidis in an ICU of a German hospital. J Antimicrob Chemother. 2018;73(5):1185-93.

24. Smith TT, Tamma PD, Do TB, Dzintars KE, Zhao Y, Cosgrove SE, et al. Prolonged linezolid use is associated with the development of linezolidresistant Enterococcus faecium. Diagn Microbiol Infect Dis. 2018;91 (2):161-3.

25. European Centre for Disease Prevention and Control (ECDC). Point prevalence survey of healthcare-associated infections and antimicrobial use in European acute care hospitals. Protocol version 5.3. Stockholm: ECDC 2016. Available from: https://ecdc.europa.eu/sites/portal/files/media/en/ publications/Publications/PPS-HAl-antimicrobial-use-EU-acute-care-hospitalsV5-3.pdf. Accessed 25 Sept 2019.

26. Behnke M, Aghdassi SJ, Hansen S, Diaz LAP, Gastmeier P, Piening B. The prevalence of nosocomial infection and antibiotic use in German hospitals. Dtsch Arztebl Int. 2017;114(50):851-7.

27. Aghdassi SJS, Gastmeier P, Piening BC, Behnke M, Pena Diaz LA, Gropmann A, et al. Antimicrobial usage in German acute care hospitals: results of the third national point prevalence survey and comparison with previous national point prevalence surveys. J Antimicrob Chemother. 2018;73(4): 1077-83.

28. Behnke M, Hansen S, Leistner R, Diaz LA, Gropmann A, Sohr D, et al. Nosocomial infection and antibiotic use: a second national prevalence study in Germany. Dtsch Arztebl Int. 2013;110(38):627-33.

29. Remschmidt C, Schroder C, Behnke M, Gastmeier P, Geffers C, Kramer TS. Continuous increase of vancomycin resistance in enterococci causing nosocomial infections in Germany - 10 years of surveillance. Antimicrob Resist Infect Control. 2018;7:54

30. Kramer TS, Schroder C, Behnke M, Aghdassi SJ, Geffers C, Gastmeier P, et al. Decrease of methicillin resistance in Staphylococcus aureus in nosocomial infections in Germany-a prospective analysis over 10 years. J Inf Secur. 2019; 78(3):215-9.

31. Dryden MS. Linezolid pharmacokinetics and pharmacodynamics in clinical treatment. Journal of Antimicrobial Chemotherapy. 2011; 66(suppl_4):iv7-iv15.

32. Guillard P, de La Blanchardiere A, Cattoir V, Fischer MO, Verdon R, SaintLorant G. Antimicrobial stewardship and linezolid. Int J Clin Pharm. 2014; 36(5):1059-68

33. Solomkin JS, Mazuski JE, Bradley JS, Rodvold KA, Goldstein EJC, Baron EJ, et al. Diagnosis and Management of Complicated Intra-abdominal Infection in adults and children: guidelines by the surgical infection society and the Infectious Diseases Society of America. Clin Infect Dis. 2010;50(2):133-64

34. Eckmann C, Dryden M, Montravers P, Kozlov R, Sganga G. Antimicrobial treatment of "complicated" intra-abdominal infections and the new IDSA 
guidelines ? A commentary and an alternative European approach according to clinical definitions. Eur J Med Res. 2011;16(3):115-26.

35. Dryden MS. Alternative clinical indications for novel antibiotics licensed for skin and soft tissue infection? Curr Opin Infect Dis. 2015;28(2):117-24.

36. Garrabou G, Soriano A, Pinos T, Casanova-Molla J, Pacheu-Grau D, Moren C, et al. Influence of Mitochondrial Genetics on the Mitochondrial Toxicity of Linezolid in Blood Cells and Skin Nerve Fibers. Antimicrob Agents Chemother. 2017;61(9).

37. Bassetti M, Righi E. Safety profiles of old and new antimicrobials for the treatment of MRSA infections. Expert Opin Drug Saf. 2016;15(4):467-81.

38. Devchand M, Kirkpatrick CMJ, Stevenson W, Garrett K, Perera D, Khumra S, et al. Evaluation of a pharmacist-led penicillin allergy de-labelling ward round: a novel antimicrobial stewardship intervention. J Antimicrob Chemother. 2019.

39. Hagiwara D, Sato K, Miyazaki M, Kamada M, Moriwaki N, Nakano T, et al. The impact of earlier intervention by an antimicrobial stewardship team for specific antimicrobials in a single weekly intervention. Int J Infect Dis. 2018; 77:34-9.

40. Garcia-Martinez L, Gracia-Ahulfinger I, Machuca I, Cantisan S, De La Fuente S, Natera C, et al. Impact of the PROVAUR stewardship programme on linezolid resistance in a tertiary university hospital: a before-and-after interventional study. J Antimicrob Chemother. 2016;71(9):2606-11.

41. Harbarth S, von Dach E, Pagani L, Macedo-Vinas M, Huttner B, Olearo F, et al. Randomized non-inferiority trial to compare trimethoprim/ sulfamethoxazole plus rifampicin versus linezolid for the treatment of MRSA infection. J Antimicrob Chemother. 2014:70(1):264-72.

42. von Dach E, Morel CM, Murthy A, Pagani L, Macedo-Vinas M, Olearo F, et al. Comparing the cost-effectiveness of linezolid to trimethoprim/ sulfamethoxazole plus rifampicin for the treatment of methicillin-resistant Staphylococcus aureus infection: a healthcare system perspective. Clin Microbiol Infect. 2017;23(9):659-66.

43. Schweickert B, Feig M, Schneider M, Willrich N, Behnke M, Peña Diaz LA, et al. Antibiotic consumption in Germany: first data of a newly implemented web-based tool for local and national surveillance. J Antimicrob Chemother. 2018;73(12):3505-15.

\section{Publisher's Note}

Springer Nature remains neutral with regard to jurisdictional claims in published maps and institutional affiliations.

Ready to submit your research? Choose BMC and benefit from:

- fast, convenient online submission

- thorough peer review by experienced researchers in your field

- rapid publication on acceptance

- support for research data, including large and complex data types

- gold Open Access which fosters wider collaboration and increased citations

- maximum visibility for your research: over $100 \mathrm{M}$ website views per year

At BMC, research is always in progress.

Learn more biomedcentral.com/submissions 